\title{
Etnografia de uma política pública: controle social pela mobilização popular
}

\section{Ethnography of a public policy: social control through community mobilization}

Claudia Fonseca*

* Universidade Federal do Rio Grande do Sul - Porto Alegre, RS, Brasil claudialwfonseca@gmail.com

Lucia Mury Scalco**

** Universidade Federal do Rio Grande do Sul - Porto Alegre, RS, Brasil Em pós-doutoramento (bolsista CNPq) luciamscalco@gmail.com

Helisa Canfield de Castro ${ }^{* * *}$

*** Universidade Federal do Rio Grande do Sul - Porto Alegre, RS, Brasil Doutoranda em Antropologia Social helisa_nut@hotmail.com 


\title{
Resumo
}

Nessa análise, partimos de um estudo, realizado entre 2014 e 2015, de "núcleos de Fome Zero" na cidade de Porto Alegre para entender os efeitos naquele contexto de um programa de entrega de alimentos a pessoas em risco de insegurança alimentar. Na primeira parte deste artigo, traçamos um perfil dos beneficiados em dois desses núcleos para ressaltar a extrema heterogeneidade da população beneficiada. Num segundo momento, estendemos nosso olhar para a dimensão organizacional do programa ao explorar a maneira com que pessoas - tanto gestores quanto lideranças comunitárias - reagem à situação problemática do momento: a irregularidade na entrega de alimentos. No início dessa investigação, usamos técnicas clássicas da pesquisa etnográfica nas próprias comunidades. Porém, a irregularidade do programa nos levou a incorporar a análise de documentos administrativos, entrevistas com gestores nos setores municipais e estaduais relevantes, e a observação do espaço político coletivo onde os representantes de núcleos debatiam suas dúvidas quinzenalmente: o Fórum Fome Zero. Sugerimos que enquanto métodos quantitativos fornecem detalhes importantes do programa (quantidade e periodicidade de entregas de alimentos), a abordagem qualitativa que privilegia as dinâmicas microterritoriais e que dá visibilidade às lideranças populares demostra outras formas de produtividade do programa ligadas a experiências de mobilização popular e controle social.

Palavras-chave: políticas públicas; distribuição de alimentos; mobilização popular; controle social.

\begin{abstract}
In this analysis, we examine the contextualized repercussions of a food distribution program among people considered to be suffering from food and nutrition insecurity in Brazil. We concentrate our efforts on neighborhood centers in the city of Porto Alegre that benefitted from the national social policy, Fome Zero, between 2014 and 2015. In the first part of this article, we sketch a profile of the participants in each of two neighborhoods in order to demonstrate the extreme heterogeneity of the program's beneficiaries. In a second moment, we extend our gaze to the program's organizational dimensions in order to explore the way in which people - administrators as well as community leaders - react to the problematic situation, evident at the time, of scarce and irregular food delivery. At the beginning of our investigation, we used classical ethnographic techniques in the local communities. However, the program's irregularity led us to include the analysis of administrative documents, interviews with administrators in the relevant sectors of municipal and state government, and observation in the collective political space where the community leaders brought their concerns on a biweekly basis: the Forum Fome Zero. We suggest that whereas quantitative methods may aptly describe the quantity and periodicity of food shipments, qualitative methods focused on microterritories and community leaders bring to light other forms of the program's productivity in the arenas of political mobilization and social control.
\end{abstract}

Keywords: public policy; food distribution; community organization; social control. 


\section{Introdução}

Este artigo surge de uma proposta de pesquisa que visava analisar os efeitos de um programa social voltado para a distribuição de alimentos entre pessoas consideradas em situação de insegurança alimentar no âmbito do Programa Fome Zero (PFZ) no Brasil. ${ }^{1}$ Nosso alvo empírico era a rede ligada à "Compra com Doação Simultânea" (CDS) do Programa de Aquisição de Alimentos (PAA) na cidade de Porto Alegre - uma rede organizada em "núcleos", incluindo associações de moradores, clubes de mães, terreiros de religião e cozinhas, espalhados pelos bairros de baixa renda. ${ }^{3}$ Para não perder de vista a diversidade dos núcleos, nossa equipe de pesquisa projetou dois estudos de caso incluindo, por um lado, uma associação de bairro que distribui alimentos para uma centena das famílias mais pobres do local e, por outro, uma cozinha comunitária anexa a uma cooperativa de recicladores que, durante a semana, fornece refeições para 120 indivíduos associados.

Nosso objetivo original era entender como a entrega de alimentos pelo programa CDS se inseria ou modificava hábitos e significados ligados às refeições familiares, aliviando ou não o grau de insegurança alimentar. Estávamos inspiradas em experiências anteriores de pesquisa, vividas no apogeu do programa

1 Este trabalho teve o apoio financeiro e científico do Conselho Nacional de Desenvolvimento Científico e Tecnológico (CNPq) e do Ministério do Desenvolvimento Social e Combate à Fome (MDS), por meio do Edital CNPq $\mathrm{n}^{\circ} 24 / 2013$, processo 456860/2013-4. A pesquisa ocorreu entre janeiro de 2014 a julho de 2015 e nossa reflexão foi elaborada, ao longo desse período, em interlocução com os gestores da Secretaria de Avaliação e Gestão da Informação (Sagi).

2 Conforme a Cartilha de compra da agricultura familiar com doação simultânea, trata-se da "modalidade do PAA na qual a cooperativa ou associação de agricultores familiares vende sua produção para o Governo, via Conab, e entrega o alimento diretamente em rede de equipamentos públicos de alimentação e nutrição (restaurantes populares, cozinhas comunitárias e bancos de alimentos) ou em rede socioassistencial (asilos, APAES e Abrigos), governamentais ou não, responsáveis pelo atendimento a populações em situação de insegurança alimentar e nutricional" (Companhia Nacional de Abastecimento, [s.d.], p. 2; ver também Brasil, 2012).

3 Conforme Araujo e Silva et al. (2013), entre as diferentes unidades recebedoras de alimentos por "Compra com Doação Simultânea" articuladas pela Conab, Brasil, cerca de $27 \%$ são associações comunitárias ou beneficentes. Apenas a categoria de escolas - pré-escola e creche (não contempladas em nossa pesquisa) - constitui uma categoria mais importante (40\%). As outras categorias incluem hospitais, instituições religiosas, asilos, etc. 
CDS em 2012, ${ }^{4}$ quando os quase 20 mil porto-alegrenses alcançados pelo programa recebiam a entrega regular de alimentos variados. ${ }^{5}$ Entretanto, em $2014 \mathrm{e}$ início de 2015 (época de nossa pesquisa), o programa passava por um momento de reformulação e a entrega de alimentos foi escassa, quando não totalmente suspensa. Assim, fomos obrigadas a reformular as perguntas de pesquisa, procurando entender como os atores ligados ao programa CDS se ajustavam à situação problemática de 2014: quais seus entendimentos sobre as causas? Quais os efeitos em termos de estratégias familiares e ação coletiva para compensar ou corrigir os problemas?

Não deixamos de retratar pessoas e famílias em risco de insegurança alimentar - assunto tratado na primeira parte deste artigo onde contrastamos a relativa estabilidade econômica dos cooperados na cozinha comunitária com a situação extremamente precária de famílias beneficiadas pela entrega de alimentos na associação de bairro. Mas logo passamos a focar o funcionamento da própria política pública, explorando a maneira com que pessoas - tanto gestores quanto lideranças comunitárias - explicam as irregularidades no programa CDS ao longo do ano 2014. Olhamos tanto para complicações administrativas quanto para problemas logísticos, sublinhando estratégias acionadas pelos beneficiados para enfrentar as dificuldades. Essa abertura de perspectiva nos leva a refletir sobre a própria materialidade dos alimentos como agente mobilizador de sentimentos cidadãos.

Essa pesquisa se inscreve numa linha de reflexão que explora o uso de métodos etnográficos para analisar o impacto de programas sociais sobre a qualidade de vida de pessoas em situações concretas (Shore, 2010). Parte de uma noção de tecnologias de governo que acentua as engrenagens cotidianas do poder - o trabalho miúdo e normalmente invisibilizado - que subjaz aos programas de intervenção destinados a "guiar, dirigir, orientar, capacitar e regular os sujeitos, populações e problemáticas" (Fonseca et al., 2016, p. 10).

4 Duas das três autoras deste artigo já estavam no circuito de distribuição de alimentos nessa época. Helisa Canfield de Castro, enquanto nutricionista, tinha atuado na Coordenadoria de Segurança Alimentar e Nutricional Sustentável (Cosans) da Prefeitura de Porto Alegre entre 2011 e 2012. Lucia Mury Scalco, enquanto pesquisadora e consultora em associações de bairro de Porto Alegre, participava na distribuição de "ranchos" (cestas básicas) oriundos do programa.

5 Números fornecidos pela Conab/RS em 14 de julho de 2015 na planilha intitulada: "PAA Porto Alegre e Metropolitana". 
A partir desse enfoque, emerge a extrema importância dos elementos da infraestrutura - as "redes construídas para facilitar o fluxo de bens, pessoas e ideias", movidas por mecanismos materiais que "moldam a natureza da rede, a velocidade e direção de seu movimento, suas temporalidades, e sua vulnerabilidade ao fracasso" (Larkin 2013, p. 328, tradução nossa). Coerente com nossa orientação analítica, focamos essa infraestrutura (técnicas administrativas, engenharias, materialidades e mediações diversas), não como sistema estabilizado, dado de antemão, e, sim, uma juntada de práticas, inseparáveis do contexto em que operam, que participa da constituição de sujeitos e processos de subjetivação (Fassin, 2009; Star, 1999).

Em anos recentes, foi realizada uma série de investigações etnográficas sobre políticas públicas no Brasil. Estudos do Programa Bolsa Família (Brites; Schabbach, 2014; Pires; Rego, 2013) têm demonstrado não só o impacto do programa social na vida material das famílias beneficiadas, mas também nas relações domésticas (em particular, o empoderamento das mulheres e crianças) e nas atitudes cidadãs (Eger; Damo, 2014; Marins, 2014; Sorj; Gomes, 2011). No que diz respeito especificamente ao Programa Fome Zero, existe um conjunto impressionante de pesquisas patrocinadas e divulgadas pelo próprio Ministério do Desenvolvimento Social e Combate à Fome (MDS) (Silva; Del Grossi; França, 2010; Vaitsman; Sousa, 2007). Há estudos instigantes sobre os aspectos simbólicos da fome crônica e os significados atribuídos ao sistema de comida em determinados lugares (Freitas; Pena, 2007). Porém, boa parte da literatura versa sobre a produção agrícola em regiões rurais, especialmente no Norte e Nordeste brasileiro. Curiosamente, os textos programáticos ou de cunho quantitativo, frequentemente escritos nos primeiros anos do programa (FAO; IDB; WB, 2002; Yazbek, 2004), continuam a ser as referências mais citadas em boa parte da literatura analítica. Com notáveis exceções (Ahlert, 2008a; Castro; Maciel, 2015), existem poucas pesquisas qualitativas sobre o funcionamento do Programa Fome Zero nas várias associações urbanas que recebem e distribuem a comida.

Justamente por causa de nossa curiosidade quanto ao papel dessas associações, tomamos particular inspiração no trabalho de Amâncio, Serafim e Dowbor (2011) que, num estudo envolvendo setores de saúde e de assistência social em São Paulo, explora formas de ação coletiva que contribuem para a qualidade de serviços públicos. Embora não usem métodos etnográficos, favorecem 
uma abordagem que põe em relevo dinâmicas do "microterritório". As autoras sugerem que, desde os anos 1990, os debates sobre participação social têm abandonado o interesse por dinâmicas microterritoriais, favorecendo, ao invés, estudos centrados em espaços institucionalizados no nível municipal e estadual. Estes, falando em termos de "controle social", versam sobre a importância de conselhos e outros órgãos operacionalizados pela articulação de diversos atores da sociedade civil junto com agentes do Estado. Porém, eclipsam do debate a ação política de associações de bairro e outras instâncias menos institucionalizadas da atuação popular.

Propondo uma perspectiva analítica que inclui esses espaços da atuação popular, as autoras se pautam numa definição ampla de "controle social" enquanto

a incidência de cidadãos sobre processos decisórios, seja mediante o fornecimento de informação, de determinação de prioridades, de implantação, seja mediante formas de avaliação e supervisão. (Gurza Lavalle; Isunza Vera, 2010, p. 31 apud Amâncio; Serafim; Dowbor, 2011, p. 287).

Apesar de essa acepção de "controle social" ser pouco conhecida na literatura antropológica, resolvemos acioná-la aqui como ponto de convergência entre nossa preocupação com a participação de cidadãos comuns nas tecnologias de governo (ver Fonseca, et al., 2016) e a linguagem usada por boa parte de nossos interlocutores no campo intersetorial das políticas públicas. Essa noção nos ajuda a tensionar a recente tendência por parte de planejadores de reduzir a "inclusão" à sua dimensão produtiva, medida em termos de estatísticas econômicas (Yazbek, 2012). A ênfase na "incidência de cidadãos sobre os processos decisórios" traz a discussão de volta para uma dimensão moral, perpassada por emoções, valores e normas, levando inelutavelmente a posicionamentos de consequência política (Fassin, 2012).

\section{O cenário de nossa pesquisa}

O ano de 2014 foi problemático para o programa CDS em Porto Alegre, mas também foi um momento propício para o estudo dos variados mecanismos de 
controle social. Sugerimos neste artigo que a abordagem qualitativa de pesquisa - incluindo métodos etnográficos - é particularmente útil para o estudo das formas menos padronizadas, mas não necessariamente menos eficazes, de controle social. Se, no início dessa investigação, usamos as técnicas clássicas da pesquisa etnográfica (observação participante, entrevistas abertas, histórias de vida) nas próprias comunidades, a questão da irregularidade do programa nos obrigou a levar nosso olhar para documentos burocráticos, o discurso de gestores em setores municipais e estaduais relevantes, e o espaço político coletivo onde os representantes de núcleos debatiam suas dúvidas quinzenalmente durante toda a época de nossa pesquisa: o Fórum Fome Zero. ${ }^{6}$

Esse fórum deve ser entendido no contexto de Porto Alegre, cidade em que os líderes comunitários se orgulham de ser pioneiros da participação popular. Já marcada pelo Orçamento Participativo iniciado nos anos 1990 durante a gestão municipal do Partido dos Trabalhadores, a municipalidade abraçara rapidamente a proposta dos núcleos Fome Zero lançada pelo governo federal a partir de 2003 e reafirmada no Projeto Brasil sem Miséria, de 2011 (Ahlert, 2008a). De 32 em 2007, o número desses núcleos cresceu, através de diferentes administrações partidárias, para 52 em 2014, cumprindo a função de mediar o repasse de alimentos oriundos de programas sociais, empresas comerciais ou outras fontes filantrópicas para indivíduos e famílias consideradas em situação de insegurança alimentar.

Já nos primeiros anos do Programa Fome Zero, surgiu o espaço conhecido como "Fórum Fome Zero" - considerado "único no país" (Relatório..., 2006) que, num prédio da prefeitura situado ao lado do mercado central, continua hoje a agregar coordenadoras ${ }^{7}$ de núcleos em reuniões quinzenais para discutir estratégias de realização dos objetivos do programa (Relatório..., 2006). Além de amparar pessoas "em risco nutricional ou risco social", o fórum tem como meta a luta pelo efetivo cumprimento dos direitos de cidadania das famílias que fazem parte dos diferentes núcleos. Através de várias medidas

6 Em todos esses espaços, apresentamos os objetivos de nosso estudo, recebendo dos participantes seu consentimento oral para inclusão na pesquisa. Tivemos o cuidado de manter o anonimato de nossos interlocutores, omitindo ou mudando seus nomes.

7 Existem alguns homens coordenadores, mas, já que a maioria esmagadora de coordenadoras do fórum são mulheres, usamos o substantivo plural no feminino. 
de combate à pobreza, incluindo programas de geração de renda, habitação, saúde e educação, ele alcança a partir de 2009 mais de 16 mil famílias (Fórum Fome Zero, 2009).

Ao longo de 2014 e início de 2015, ao seguir as lideranças comunitárias que clamavam pela retomada do programa CDS, chegamos na importância central desse fórum que, correndo paralelo aos diversos conselhos setoriais e mesmo ao comitê gestor previstos na estrutura formal do programa, parece ser o palco principal de reivindicações populares. Enquanto métodos quantitativos fornecem detalhes pontuais do programa (quantidade e periodicidade de entregas de alimentos), a abordagem qualitativa que privilegia as dinâmicas microterritoriais e que dá visibilidade às lideranças populares demostra outras formas de produtividade do programa - ligadas em particular a experiências de mobilização popular e controle social.

\section{Renda fixa e aspirações à ascensão socioeconômica na cozinha comunitária da Unidade de Triagem e Compostagem}

Diversas pesquisas apontam para a possibilidade de os efeitos de uma política social variarem conforme as especificidades da população beneficiada - daí, a necessidade de estudos que levam em consideração as particularidades do contexto local (Amâncio; Serafim; Dowbor, 2011; Pires; Rego, 2013). Morton (2013), na sua análise do Programa Bolsa Família no sertão da Bahia, emprega técnicas etnográficas para colocar em perspectiva a heterogeneidade da população beneficiada. Chega à conclusão de que o "empoderamento" das mulheres que recebem o benefício, efeito constatado em diversos estudos (Eger; Damo, 2014; Pires, 2013; Pires; Jardim, 2014), ocorre principalmente naquelas famílias onde existe uma renda garantida mínima - muitas vezes, fruto do trabalho masculino. Essa relativa estabilidade econômica - o que o autor chama de "acesso à permanência" - seria o que permite às mulheres investirem o dinheiro do Bolsa não em necessidades imediatas e, sim, em bens duradouros identificados como sendo "da mulher". Esse impacto diferencial da política social conforme o nível de estabilidade econômica, abrindo ou não a possibilidade de usar o benefício para planejar bens inseridos em circuitos "de longo prazo", se mostra pertinente para entender as diferenças entre os dois núcleos do programa CDS que estudamos em Porto Alegre. 
No primeiro núcleo, lidamos com uma cozinha comunitária anexa a uma cooperativa de recicladores de lixo onde, não obstante um padrão de vida extremamente modesto, as pessoas têm uma renda estável garantida. ${ }^{8}$ Lembramos da diversidade do próprio universo de cozinhas comunitárias. Em 2004, o governo federal promoveu por edital público a instalação de cozinhas comunitárias nas periferias das grandes capitais nacionais sob a bandeira da Estratégia Fome Zero. A prefeitura de Porto Alegre, na ocasião, concorreu ao edital e foi contemplada com 24 equipamentos a serem distribuídos pela gestão municipal (Ahlert, 2008b). Na época de nossa pesquisa, vários desses equipamentos estavam parados ou funcionando numa escala reduzida. A maioria das cozinhas comunitárias ainda operantes era gerenciada por instituições religiosas onde havia uma clara diferenciação entre administradores e beneficiados da proposta. A cozinha comunitária anexa à Unidade de Triagem e Compostagem (UTC) era uma das únicas unidades criadas e administradas pelos próprios beneficiados.

Localizada na Lomba do Pinheiro, $15 \mathrm{~km}$ a leste do centro de Porto Alegre, com local e maquinário concedidos pela prefeitura, a UTC é operada por uma centena de moradores do bairro que trabalham desde 2001 para triar os materiais reaproveitáveis (lixo seco) trazidos pelo Departamento Municipal de Limpeza Urbana (Castro, 2015). Todo mês, a prefeitura repassa uma quantia fixa para a UTC (R\$ 18.000,00 em 2014) - quantia que, junto com os ingressos proporcionados pela venda dos materiais recicláveis, permite pagar, além dos custos de manutenção, cerca de um salário mínimo mensal (R\$ 750,00) a cada associado. A maioria de associados completa esse ingresso monetário com bicos (no fim de semana) e auxílios sociais.

A equipe de direção, eleita de dois em dois anos, gerencia tanto o galpão de trabalho quanto a cozinha. De segunda a sábado, a maioria dos associados chega às $6 \mathrm{~h}$ da manhã para tomar café na cozinha da UTC; todos almoçam e quase todos comem lanche na cozinha comunitária antes de ir para casa às 16h. Em princípio a cozinha deve ser abastecida com alimentos doados do CDS, através da prefeitura (Coordenadoria de Segurança Alimentar e Nutricional - Cosans) ou da Companhia Nacional de Abastecimento do Rio Grande do Sul (Conab/RS).

8 Essa pesquisa desembocou na dissertação de mestrado de Helisa Canfield de Castro (2015), realizada no PPG de Antropologia Social, UFRGS, sob a orientação da Professora Maria Eunice Maciel. 
Na cozinha comunitária da UTC, os alimentos entregues pelo CDS se destinam principalmente ao consumo no refeitório pelos associados, todos adultos. Enquanto o soldo mensal que os associados ganham é geralmente socializado em família, a comida é um benefício reservado ao indivíduo que trabalha no galpão. Embora sem carteira assinada ou direitos celetistas, os associados têm renda fixa, comida garantida e alguns estão projetando trajetórias de ascensão social. Se, à primeira vista, essa população parece menos necessitada do que as de outros núcleos do Programa Fome Zero em Porto Alegre, deve-se lembrar que ela inclui muitas pessoas que, antes da cozinha comunitária, levavam marmita de casa, com conteúdo e qualidade variáveis, para comer no lugar de triagem - isto é, no meio do lixo. Hoje, além de ter higienizado e regularizado as refeições dos recicladores, a cozinha comunitária atende a um número não desprezível de associados solteiros ou de idade avançada - alguns dos quais não teriam nem disposição nem equipamento para preparar refeições nas suas casas (Castro, 2015).

Conforme a presidente eleita da UTC nos relatou, houve uma época em que as entregas de alimentos pelo programa CDS garantiam um cardápio farto e variado aos participantes da cozinha comunitária. Quando, em 2014, as entregas escassearam, foi possível, entre doações de outras fontes e compras com dinheiro da venda dos produtos residuais reciclados, garantir uma provisão mais ou menos regular de arroz e feijão. Porém, a cozinha não oferecia mais nada além desses produtos básicos. Para completar as refeições, cada cooperado passou então a trazer uma pequena porção de alimentos (carne, tomate, polenta) a ser preparada por uma funcionária na cozinha designada especificamente para a preparação dessas "misturas". Em geral, os ingredientes da mistura eram comprados nos pequenos estabelecimentos do bairro que aceitavam pagamento a prazo, ou que, mediante convênio com a UTC, deduziam a soma devida diretamente do dinheiro pago pela unidade no final do mês.

Reconhece-se que as "misturas" não foram previstas no projeto original das cozinhas. Pelo contrário, a orientação era desencorajar a presença de alimentos cuja origem não podia ser verificada e higienicamente garantida. Tampouco há equipamento para facilitar o processo. As cozinheiras tiveram que deixar de lado os grandes caldeirões industriais e procurar pequenas panelas do tamanho de uma porção de comida. Mas a instituição da "mistura" foi uma maneira para a cozinha comunitária continuar a desempenhar um lugar central na saúde alimentar do grupo. E ainda agradou ao gosto dos que queriam algo mais 
"forte" (com mais sal e mais fritura) do que o cardápio das refeições massificadas vigiadas por nutricionistas (Castro, 2015).

Em suma, ao longo de 2014, os associados da UTC se queixaram da mesma forma que os demais núcleos da irregularidade da entrega de alimentos via o programa CDS. Entretanto, graças a uma renda garantida e certas estratégias coletivas, ainda conseguiram manter o que a maioria considerava um nível satisfatório de segurança (qualidade e variedade) alimentar. A situação do segundo núcleo que pesquisamos era outra.

\section{As intempéries da vida cotidiana na Associação Comunitária do Morro da Cruz}

A Associação Comunitária do Morro da Cruz, alvo de nosso segundo estudo de caso, é sediada numa estrutura de tijolos sem reboco (reformada e ampliada diversas vezes pelos próprios moradores), construída num terreno doado pela prefeitura no alto de um morro a cerca de $8 \mathrm{~km}$ do centro da cidade. $O$ bairro reúne, além de loteamentos populares antigos e áreas de ocupação mais recentes, alguns prédios de apartamentos construídos ao longo de diferentes políticas públicas de habitação para a população de baixa renda. A atual diretoria, constituída por pessoas com longa experiência na entrega de alimentos, foi eleita em 2008 e reeleita a cada dois anos desde então. Desenvolve projetos na área da cultura, geração de renda e solidariedade comunitária. Além de um modesto salão de festas (cujo aluguel fornece a principal fonte de renda da associação), há uma pequena sala com máquinas de costura e retalhos de tecido para proporcionar atividades de artesanato. Outra saleta serve como despejo para computadores velhos, doados por empresas, prontos para serem reformados ou fornecer partes avulsas para máquinas estragadas. Mas é nos fundos do prédio que fica o ponto de atração mais regular: trata-se de uma grande cozinha, montada com aparelhos doados, onde meia dúzia de mulheres se revezam para preparar os episódicos almoços e chás, geralmente pagos com a contribuição dos próprios participantes. ${ }^{9}$

9 Apesar de repetidas tentativas, ainda não foi possível incluir esse espaço no programa municipal de cozinhas comunitárias, pois a diretoria da associação não consegue adequar as condições do prédio às exigências da Agência Nacional de Vigilância Sanitária (Anvisa). 
Entre suas muitas atividades, a associação é responsável pela distribuição dos alimentos CDS para as famílias mais pobres do bairro. A lista de beneficiados varia em função das frequentes mudanças - ou de moradia ou de situação financeira - dos cadastrados. Uma consulta à lista mostra que $95 \%$ dos beneficiados com alimentos são mulheres, a grande maioria com crianças pequenas ao seu encargo. Dos 500 membros familiares alcançados pelo programa, mais da metade tem menos de 14 anos e menos de $1 \%$ tem acima de 65 anos. Em outras palavras, os alimentos distribuídos pela associação, geralmente preparados e consumidos nas unidades domiciliares, beneficiam principalmente crianças e suas cuidadoras.

No Morro da Cruz, concentramos nossas visitas domiciliares no local considerado mais precário do bairro: um "beco" na encosta íngreme do morro onde existe uma ocupação com três dúzias de moradias sem serviço regularizado de luz, de água ou de coleta de lixo. Aqui, a grande maioria de homens adultos - geralmente analfabetos ou de baixa escolaridade - trabalha em atividades manuais mal remuneradas e de grande instabilidade. As mulheres encontram "bicos" como faxineiras, mas também procuram trabalho com horas flexíveis (vendendo roupas, produtos Avon, ou mesmo "juntando latinhas") que lhes permite garantir simultaneamente as responsabilidades domésticas. A renda mais estável, oriunda de auxílios sociais tais como Bolsa Família, Brasil Carinhoso, Ação Rua e "pensões" de BPC,10 é gasta antes de tudo na compra de comida. Como diz uma mãe de família: "Comemos o Bolsa Família" (ver também Morton, 2013; Pires; Jardim, 2014). Em vez de frequentar os grandes supermercados onde encontrariam produtos mais baratos, as pessoas fazem compras nos minimercados locais ou então com "os nordestinos" (uma rede do comércio informal que aceita vender "fiado" e faz entregas a domicílio).

10 O Benefício de Prestação Continuada é uma medida federal que "garante a transferência mensal de 1 (um) salário mínimo à pessoa idosa com 65 anos ou mais e à pessoa com deficiência de qualquer idade" que não possui meios de se sustentar ou de ser sustentada pela família (Brasil, 2015). O Brasil Carinhoso, iniciado pelo governo federal em 2012, garante a cada um dos membros da família que tem ao menos uma criança entre 0 e 6 anos, "recursos suficientes para viver com mais de R\$ 70 reais" (Discurso..., 2012). Ação Rua é um programa municipal de transferência condicional de renda, em suplemento ao Bolsa Família, que paga às famílias de crianças em idade escolar tendo passado por situação de rua, mediante a frequência comprovada à escola (Porto Alegre, [s.d.]). 
A descrição sumária de três famílias alcançadas pelas atividades da associação de bairro do Morro da Cruz serve para evocar a maneira com que a insegurança alimentar faz parte de uma situação globalmente precária onde o benefício proporcionado pelos programas sociais serve antes de tudo para suprir necessidades imediatas.

Caso 1: Dona Luzia, 63 anos, mora desde a infância no mesmo barraco de madeira na descida do morro. Com sua pensão de viúva (um salário mínimo) e o Bolsa Família que recebe para quatro de seus seis netos, sustenta uma família de oito. Sua filha de 25 anos de idade não recebe nenhum auxílio para ajudar nas despesas dos dois filhos em idade pré-escolar. A jovem mãe demorou para fazer os documentos exigidos para pleitear o Bolsa Família e, depois de quase um ano, ainda espera pela "resposta de Brasília". Diz que, sem ter onde deixar as crianças, é difícil arranjar um emprego.

Ao longo de 2014, a renda da família - em vez de crescer, como todos esperavam - diminuiu. Um dos netos de Dona Luzia voltou para a casa da mãe (causando uma redução no valor do Bolsa Família que Dona Luzia recebe) e veio juntar-se à unidade doméstica um irmão cinquentão desempregado, recém-separado. Coroando uma situação já precária, durante um temporal no fim do ano, caiu uma árvore que derrubou um muro da casa. Com água e eletricidade enjambradas via "gatos", Dona Luzia estava tendo que achar uma maneira para consertar canos arrebentados, telhado furado e fiação elétrica quase pegando fogo. É só graças às doações de vizinhos solidários - que ajudavam com roupa, material de construção, serviços de pedreiro e comida (para completar refeições cada vez mais escassas) - que Dona Luzia conseguia manter a família intacta.

Caso 2: Cézar, 44 anos, morador do local há mais de 20 anos, vive com sua mulher e seis dos oito filhos. Sem emprego formal e autodidata, ele vive de biscates, consertando computadores e fazendo pequenos serviços de informática para os vizinhos. Sua caçula, hoje com dois anos de idade, nasceu com grave debilidade neurológica, requerendo alimentação especial além de cuidados constantes. Devido à necessidade de acompanhar a filha nos frequentes internamentos hospitalares, nem Cézar, nem sua mulher mantêm um emprego regular. Só recentemente a família conseguiu o Benefício de Prestação Continuada para a menina, mas esse auxílio provocou a redução nos outros auxílios que a família recebe (Bolsa Família e Brasil Carinhoso). 
O drama nessa família é garantir energia elétrica para o funcionamento do aparelho de respiração artificial que mantém a caçula com vida. Cézar já pediu repetidamente uma ligação na companhia elétrica para substituir o "gato" com o qual vivem há duas décadas, mas a companhia nega porque a família vive numa "área verde". Outra preocupação perene é encontrar dinheiro para a compra do botijão de gás, sem o qual não sai refeição. Mesmo conseguindo o "rancho" básico (doado ou comprado), Cézar e sua mulher são frequentemente obrigados a cozinhar com uma "espiriteira" de álcool ou um fogo de chão alimentado com lenha encontrada no mato. Vivem com medo de a casa pegar fogo, tal como aconteceu no terreno da vizinha, Rosana.

Caso 3: Rosana, 43 anos, morava no início de 2014 com seus oito filhos e seu companheiro (pai dos últimos dois filhos), Manuel. Há cinco anos, depois de ser removida de uma vila de ocupação, a família chegou ao beco onde morava o pai de Manuel. Quando conhecemos o casal, Manuel não conseguia trabalho regular por causa de óbvios problemas de saúde (ostentava uma bolsa coletora de urina atada no cinto). A mãe e um dos filhos já tinham passado por tratamento de tuberculose. A principal fonte de renda da família era da venda de produtos recicláveis catados por Manuel no lixo, além do dinheiro dos programas Bolsa Família, Brasil Carinhoso e Ação Rua. As crianças em idade escolar costumavam almoçar no colégio e recebiam lanche no Serviço de Apoio Socioeducativo (Sase) que frequentavam no turno inverso ao da escola.

Em junho daquele ano, um incêndio provocado pela instalação elétrica enjambrada queimou a casa e tudo o que estava dentro. Graças à solidariedade dos vizinhos e aos materiais doados pela prefeitura para refazer a casa, Rosana podia relatar, já em outubro, que via de regra a família comia quatro refeições por dia (incluindo café da tarde). Entretanto, a última vez que encontramos Rosana (em junho de 2015), o delicado equilíbrio de sua rotina doméstica tinha ruído. Depois de muita briga, seu companheiro (e a contribuição dele à renda familiar) sumira. Um dos filhos tinha desistido das atividades extraturno, perdendo direito ao dinheiro do Ação Rua. A família estava com dívida de dois meses no comércio onde comprava alimentos e a generosidade dos vizinhos (em cujas casas as crianças pediam comida) estava se esgotando. Rosana nos confiou que estava se tratando com remédios psiquiátricos para conter seus impulsos violentos diante das crianças que "miavam de fome". 
Em suma, entre os recipientes do Programa CDS nesse bairro, encontramos pessoas que, mesmo recebendo auxílios sociais, vivem num precário equilíbrio econômico. Qualquer perturbação da rotina (doença, morte, tempestade, incêndio, separação conjugal, etc.) pode submeter a família ao risco de grave insegurança alimentar. ${ }^{11}$ Algumas dessas pessoas lembram com entusiasmo dos "ranchos" que recebiam via a associação de bairro quando as entregas do programa CDS eram regulares. Tinham então a possibilidade não só de contar com produtos básicos de alimentação cotidiana (arroz, feijão, açúcar), mas também de variar o cardápio com frutos e legumes que não constam do cardápio normal. Contudo, no ano da pesquisa, à medida que a entrega de alimentos escasseava, a insegurança alimentar voltou a ser uma ameaça real.

\section{O foco nas articulações administrativas e logísticas do programa}

A justaposição das descrições de pessoas nesses dois núcleos sublinha a importância da regularidade e previsibilidade dos ingressos (financeiros e alimentares) para produzir um efeito duradouro no bem-estar da população. Um desafio que se apresentava aos pesquisadores era de entender as ramificações da irregularidade do próprio programa social, CDS, em 2014. Para tanto, passamos a examinar os processos administrativos desse programa, esboçando nossos primeiros passos numa "etnografia da infraestrutura" (Star, 1999).

\section{"Alterações na periodicidade" do programa: complicações administrativas}

A execução de um programa como o "Compra com Doação Simultânea" do PAA envolve a articulação de acordos entre o governo federal e instâncias de governos estaduais e municipais, de termos de adesão com os fornecedores de alimentos (produtores da agricultura familiar e cooperativas agrícolas) e de parcerias com agências mediadoras beneficiadas (organizações filantrópicas,

11 Uma pesquisa realizada em 2014 entre 555 famílias porto-alegrenses em situação de vulnerabilidade social mostrou que, apesar de uma renda familiar média bastante elevada (um pouco mais de R\$ 1.000,00), quatro em dez das pessoas entrevistadas sofrem de insegurança alimentar do tipo grave (Comim, 2014). 
associações de bairro, etc.). Não há de estranhar que, nesse emaranhado de operações, encontrem-se articulações burocráticas e logísticas que trazem complicações ao bom andamento do sistema.

Incitadas pelos financiadores dessa pesquisa (representados por técnicos do MDS), procuramos entender exatamente quais articulações do sistema CDS estavam apresentando problemas. Nossa primeira ideia era procurar nos vários conselhos e mesmo no Fórum Fome Zero por esclarecimentos. Frustradas pela natureza incompleta e fragmentada das informações fornecidas, iniciamos contato com gestores nas instâncias municipal e estadual relevantes. Lá, apesar de ninguém mencionar os cortes orçamentários no programa CDS que viríamos a descobrir mais tarde ${ }^{12}$ encontramos colaboradores que falaram com surpreendente candor de outros desafios que enfrentavam.

A partir de planilhas disponibilizadas pela Conab/RS, pudemos ter uma ideia da periodicidade da entrega de alimentos CDS por esse órgão estadual durante o ano de 2014. Trazemos aqui o exemplo da cozinha comunitária da UTC:

- Janeiro a junho: nenhuma entrega

- Julho, dia 3: abóbora e mandioca; dia 17: laranjas, batatas, mandioca, arroz

- Agosto, dia 11: abóbora, batatas, mandioca e leite de vaca

- Setembro, dia 4: arroz, mandioca, laranja, batatas

- Outubro: nenhuma entrega

- Novembro: nenhuma entrega

- Dezembro, dia 8: laranja, arroz e leite de vaca

As planilhas mostraram que, tal como nos outros núcleos, não houve na UTC nenhum alimento distribuído pela Conab/RS em oito dos 12 meses de 2014. O leite (de vaca, em oposição a "bebida láctea") foi entregue apenas duas vezes (em agosto e dezembro); arroz veio em junho, setembro e dezembro, mas - a julgar pelo valor de entrega ( $\mathrm{R} \$ 572,00$ a cada vez) - não em quantia suficiente para se estender de uma entrega a outra.

É importante frisar que a Conab/RS não é a única fonte de alimentos dos núcleos. A "Compra com Doação Simultânea" do PAA funciona também via

12 Ver Grisa e Porto (2015) sobre o dramático corte de verbas federais para o PAA entre 2012 (apogeu do programa) e 2013. 
prefeitura municipal, através da Coordenaria Municipal de Segurança Alimentar Nutricional Sustentável (Cosans), que estabelece termos de adesão com produtores de agricultura familiar do próprio município. Em 2012, no auge do sistema, os núcleos beneficiados podiam receber simultaneamente alimentos do órgão estadual e do órgão municipal. Contudo, em julho de 2015, em entrevista com gestores do município, recebemos a informação de que havia cerca de dois anos que o município não entregava alimentos aos núcleos por causa de complicações administrativas. ${ }^{13}$

Através de visitas e e-mails trocados com os responsáveis administrativos, a natureza dessas "complicações administrativas" se tornou mais clara. Em troca de correspondência conosco no início de julho 2015, a responsável pela Conab/RS descreve uma série de problemas que tinham impedido a entrega regular de alimentos no ano anterior. Em primeiro lugar, conta que houve demora na assinatura dos "termos de adesão" com os produtores rurais. Esses termos só podem ser assinados depois do cumprimento de uma série de etapas administrativas. Por exemplo, o acordo entre o órgão federal (MDS) e os governos estaduais deve ser renegociado a cada cinco anos. Só então os municípios podem estabelecer termos de adesão com os agricultores. Por causa da exigência que haja prestação de contas de todos os termos assinados durante determinado exercício antes de começar um novo ciclo de contratos, é previsível certa espera entre um exercício e outro. Recomenda-se que o agricultor só plante a cultura contratada depois de assinar o termo de adesão. Assim, à demora administrativa soma-se a demora provocada pelo próprio calendário agrícola, tornando a entrega regular de alimentos uma tarefa particularmente desafiante.

Em segundo lugar, o e-mail da Conab apontou "problemas na fiscalização do programa de leite" que teriam provocado a suspensão da entrega "até a solução dos problemas". De fato, está se referindo a supostos casos de corrupção que ocorreram em outros estados. Procurando prevenir problemas futuros, o MDS, junto com outros órgãos federais, publicou no fim de outubro de 2013, a resolução $n^{\circ} 62$ (Brasil, 2013), estabelecendo novas orientações administrativas quanto à destinação dos alimentos adquiridos com recursos do PAA. Nesse

13 Conforme relatos dos representantes no Fórum Fome Zero, outro programa PAA do município, que lidava especificamente com a entrega de alimentos para escolas e creches, funcionava com relativa regularidade. 
clima de moralização, houve pequenos ajustes que acabaram provocando efeitos imprevistos.

Por exemplo, em Porto Alegre, para evitar a possibilidade de uma mesma pessoa receber alimentos em dois ou mais núcleos, passou-se em 2014 a exigir dos beneficiados com alimentos um novo documento - o Número de Identificação Social (NIS). ${ }^{14}$ Essa exigência aparentemente simples provocou tensões entre coordenadoras locais tentando cobrar o documento protocolar e beneficiárias que se viram ameaçadas de ser cortadas da lista. ${ }^{15}$ Cabe lembrar que, em muitas famílias, a geração adulta inclui apenas pessoas de baixa escolaridade, trabalhadores do setor informal da economia, para as quais a confecção de documentos tais como carteira de identidade, $\mathrm{CPF}$, título eleitoral e carteira de trabalho não é nada evidente. Enquanto alguns indivíduos mantêm seus documentos pessoais (e os de seus familiares) cuidadosamente guardados em sacos plásticos enfiados no fundo de uma gaveta, outros já perderam esses documentos ou nunca os possuíram (Fonseca; Scalco, 2015). Diante dessa situação, o que, aos olhos dos administradores, parece ser uma "mera" exigência técnica pode representar um obstáculo quase insuperável para os beneficiados em potencial.

Lidar com a burocracia tampouco é simples para as coordenadoras de núcleo que, geralmente, não possuem mais que ensino fundamental. Nenhum dos núcleos pesquisados usa computador para ajudar na organização administrativa das atividades. Tudo é registrado a caneta, muitas vezes em folhas soltas rasgadas de cadernos escolares e guardadas em pastas de cartolina. $\mathrm{Na}$ associação de bairro que pesquisamos, encontra-se nessas pastas uma quantidade impressionante de listas de pessoas que receberam alimentos - mas cada lista é organizada com informações diferentes e, frequentemente, sem data. Na cozinha comunitária, encontram-se pastas com cópias do recebimento de entrega de uma série de produtos fornecidos por entidades públicas e privadas.

14 O NIS, instituído em 2001 pelo decreto $\mathrm{n}^{\circ} 3.877$ (Brasil, 2001) no âmbito do Cadastro Único, e reafirmado em 2007 pelo decreto $\mathrm{n}^{\circ} 6.135$ (Brasil, 2007), foi projetado para facilitar a administração de programas sociais. Entretanto, nos casos observados por nós em Porto Alegre, o NIS só passou a ser um elemento conhecido e contestado da vida dos mais pobres a partir de 2014, com o reforço das exigências do programa CDS.

15 Durante a observação de uma manhã de distribuição de alimentos na associação do Morro da Cruz, vimos a coordenadora se justificar reiteradamente que ela "arriscava ir presa" se aceitasse entregar alimentos sem que a beneficiada fornecesse um NIS. 
A utilidade desses documentos sem ordem de classificação está longe de ser clara. Parecem ficar à espera da chegada eventual de pessoas como a "mulher da caneta" (certa funcionária da prefeitura).

Os efeitos imprevistos da resolução ${ }^{\circ} 62$ (Brasil, 2013) assumem forma concreta na correspondência da gestora da Conab quando ela menciona, como terceiro motivo para "alterações na periodicidade" do programa, a falta de registro de certos núcleos no Conselho Municipal de Assistência Social (CMAS). Entre outras orientações, a resolução reforçou a exigência de que, para beneficiar da entrega de alimentos CDS, a entidade - isto é, todo núcleo - devia ser inscrita no CMAS. Em Porto Alegre, seguindo resolução municipal no 176/2013 (Porto Alegre, 2013), essa inscrição exigiria uma dúzia de documentos, incluindo, além de plano de ação da entidade (com objetivos, finalidades, etc.), cópias autenticadas do estatuto social (atos constitutivos) devidamente registradas em cartório de registros especiais, CNPJ e atas de eleição e posse da atual diretoria. Seguidas à risca, essas exigências provocariam o término da participação no CDS de boa parte dos 52 núcleos existentes em Porto Alegre, a maioria dos quais distribuem alimentos há mais de dez anos. (É significativo que a presidente da associação de bairro que pesquisamos, apesar de ser conselheira do CMAS, nunca conseguiu reunir a documentação necessária para registrar sua própria associação.)

Em suma, a particular conjuntura administrativa de 2014 parece ter criado obstáculos não só para os beneficiários e as associações que recebem alimentos. Também trouxe complicações para os gestores municipais e estaduais. É irônico que as novas medidas administrativas promulgadas em resposta a adversidades circunstanciais, em vez de sanar a situação, podem ter agravado problemas já presentes no sistema.

\section{Desafios logísticos: a produtividade das queixas}

Enquanto os gestores que encontramos eram, na sua maioria, profissionais qualificados com longa história na participação e militância em conselhos setoriais ligados ao combate à insegurança alimentar e nutricional, os líderes comunitários com os quais convivemos, mais "generalistas", investiam suas energias em outra arena de participação: o Fórum Fome Zero. Ao participar das reuniões desse fórum, descobrimos que boa parte das queixas sobre o programa 
CDS era concentrada num tipo de problema pouco comentado nas repartições públicas: o dos desafios logísticos da entrega de alimentos.

Conforme as coordenadoras dos núcleos, muitos dos alimentos vêm de longe - de cooperativas agrícolas em Santana de Livramento, por exemplo, que ficam a mais de $500 \mathrm{~km}$ de Porto Alegre. São transportados em caminhões contratados, em geral, pelas cooperativas, sem refrigeração ou outro tipo de acondicionamento adequado. Os motoristas chegam a Porto Alegre com uma lista de endereços, mas se perdem facilmente e, depois de uma noite inteira na estrada, podem demorar mais um dia para encontrar todos os lugares de destino. Até lá, os produtos perecíveis, tais como leite, laranjas e uvas podem ter sofrido considerável dano. Alguns motoristas se negam a entrar em certos bairros, alegando que, lá, já foram pegos em tiroteio. Em todo caso, geralmente não aceitam fazer o trabalho de descarregamento, esperando ser recebidos por voluntários responsabilizados por essa tarefa. As coordenadoras de núcleo que devem receber a mercadoria se queixam que são avisadas só na véspera da entrega. As associações menores são frequentemente obrigadas a buscar o produto em algum ponto centralizado da cidade. E, para essas pessoas (cujas famílias raramente possuem carro), não é evidente onde encontrar um voluntário para carregar e transportar $300 \mathrm{~kg}$ de arroz (por exemplo) até o centro comunitário.

Mesmo quando os caminhoneiros vêm diretamente para o centro comunitário indicado, pode haver problemas. As coordenadoras, sem saber exatamente a que horas vai chegar a entrega, devem encontrar alguém para ficar no local de plantão - das $6 \mathrm{~h}$ da manhã até de noite. Os alimentos chegam muitas vezes sem serem empacotados - as uvas, por exemplo, sendo despejadas diretamente no chão. A associação não tem lugar seguro para estocar os produtos; tampouco possui sacolas em que os beneficiados possam carregar os alimentos para casa. Ainda há a questão de como avisar os participantes do programa que os alimentos estão disponíveis. A única maneira para alertá-los é colocar um aviso escrito na porta da associação e esperar que todo mundo veja.

Durante as duas a três horas do fórum, cada coordenadora tem lugar para colocar suas queixas, mas também aproveita a oportunidade para dar publicidade às soluções criativas que seu núcleo inventa para minimizar os estragos da logística falha, da quantia incerta e da qualidade problemática dos 
alimentos. É subentendido que os beneficiados se ofendem quando sentem que, por serem pobres, estão recebendo migalhas (quantidades irrisórias) ou mercadorias inferiores, e as coordenadoras se orgulham das soluções que improvisam para solucionar situações problemáticas. Uma das lideranças se lembra da vez que "tinha apenas dois quilos de arroz por família; mal valia a pena as pessoas virem buscar". Teve que selecionar as famílias mais necessitadas, deixando outras fora, para compor um rancho que "valia a pena". Em outro local, um núcleo com mais de cem pessoas inscritas, chegaram apenas dez melancias. A coordenadora conta como fatiaram as frutas na hora e fizeram merenda para quem estava presente na associação. Quanto a produtos avariados, ouvimos várias vezes histórias como estas: "As uvas eram imprestáveis. Que fizemos com elas? Jarras e jarras de geleia!"; "O leite chegou completamente azedo. Não pensamos duas vezes. Fizemos ambrosia para o dia seguinte."

No Fórum Fome Zero, porém, os esforços para encontrar políticas de ação vão bem além das táticas improvisadas de cada núcleo. A maioria das lideranças comunitárias tem longa experiência em diferentes redes associativas - de assistência social, de saúde, de habitação - e traz ideias pertinentes durante as reuniões quinzenais. Participantes esclarecem detalhes sobre a colaboração com diferentes elos da rede de abastecimento (o Banco de Alimentos da Fiergs, doações de empresas particulares, etc.), sugerindo pistas diversificadas para suprir as lacunas deixadas pela irregularidade dos programas rotineiros. A diretoria do fórum, que deve possuir certa competência para a articulação dos diferentes recursos públicos, filantrópicos e empresariais, também representa o grupo nos diversos conselhos setoriais do governo (de segurança alimentar, de assistência social, etc.), socializando informações úteis. E é no fórum que se organizam as ações coletivas, quando, por exemplo, as coordenadoras decidem em massa visitar a Conab para apresentar suas demandas.

Até 2014, a exigência de que cada núcleo fosse inscrito no Conselho Municipal de Assistência Social foi contornada por uma estratégia coletiva forjada pelo grupo. Os sete ou oito núcleos com registro adequado serviam, cada um, de "guarda-chuva" para até meia dúzia de núcleos sem documentos. Em 2014, nas planilhas Conab registrando entrega de alimentos, os 52 núcleos eram condensados em oito grupos. No grupo da Associação do Morro, havia nove núcleos somando mais de 700 famílias. Já que as planilhas registravam a entrega de alimentos apenas à "cabeça" de cada um dos oito grupos, sem descrever como 
os produtos foram repartidos entre os demais núcleos, não era possível saber precisamente quem recebeu o quê. Contudo, se, por um lado, o sistema "guarda-chuva" dificulta a conferência da distribuição exata de alimentos, por outro, através do Fórum de Fome Zero, opera uma forma de controle social popular que garante a vigilância meticulosa do sistema.

Observa-se nas reuniões como as coordenadoras comparam notas. Os casos de corrupção envolvendo o programa em outros estados chegam ao conhecimento dos beneficiários, atiçando dúvidas. Acusa-se o "governo"16 de indiferença ou corrupção. Mas também se acusam indivíduos do próprio grupo. Fofocas surgidas nos bastidores sobre uma ou outra coordenadora local querendo "se aproveitar" do programa se tornam públicas, abrindo a possiblidade de investigações administrativas e eventualmente expulsão do sistema. Não só se controla a quantia de produtos entregue a cada núcleo, também se questionam detalhes tais como o itinerário dos caminhoneiros que faz com que os alimentos cheguem mais cedo, e portanto, mais frescos, em certos bairros. Insinua-se que os produtos estão chegando em Porto Alegre em quantidade e regularidade normais, mas "alguém" os está comercializando ou, de outra maneira, usando-os em benefício próprio. $\mathrm{O}$ tom do debate pode ser agressivo e as confrontações, prefaciadas de frases como "vou ser franca", criam tensões acirradas. Mais de uma vez, a presidente eleita do fórum, sentindo-se alvo de críticas, ameaçou se demitir. Ao que tudo indica, a frustração diante da entrega problemática de alimentos provindos do CDS redunda em suspeitas e acusações em todos os níveis.

Considerando o tom acalorado do debate, não é surpreendente que os gestores municipais e estaduais participem apenas episodicamente nas reuniões do fórum. Como uma das gestoras me explicou: "Cansei de ser alvo de acusações." (Existe uma certa simetria entre a reticência dos gestores em relação ao fórum e o comportamento reticente dos líderes comunitários nos conselhos oficiais. Nas raras ocasiões em que assistimos a uma reunião do comitê gestor onde uma representante do fórum participava junto com funcionários do estado e

16 Em debates do Fórum Fome Zero, assim como em conversas junto às pessoas beneficiadas nos bairros, explicitar exatamente qual órgão governamental é responsável pelas entregas alimentares parece ser de pouca ou nenhuma relevância. Na fala dessas pessoas, o termo "governo" pode estar designando organizações filantrópicas ou setores públicos (da administração municipal, estadual ou federal). 
outras autoridades, a representante se mantinha curiosamente calada.) Por outro lado, entre as lideranças comunitárias, o espaço do fórum continua a agir como um polo de atração, lotando a sala com representantes de praticamente 100\% dos núcleos em cada reunião.

Em suma, arguimos que o fórum demonstra uma dinâmica que privilegia a participação dos líderes comunitários na fiscalização da política pública envolvendo a distribuição de alimentos. A observação de debates nesse espaço nos convenceu de que, aos olhos dessas lideranças, a lisura do processo não é garantida tanto por mecanismos burocráticos (NIS, o registro no CMAS) quanto pela vigilância constante exercida por esse grupo. É essa participação, em complemento aos controles administrativos formais, que cria confiança e confere legitimidade à política pública envolvendo a distribuição de alimentos. As queixas perenes que registramos podem ser vistas como evidência justamente da produtividade do programa - mesmo (ou, talvez, particularmente) em um momento de adversidade. É em instâncias tais como o Fórum Fome Zero que essas queixas vêm à tona, proferidas por pessoas trabalhando juntas para a realização de uma política social democrática e apostando que a participação delas pode fazer uma diferença.

\section{A mobilização popular}

Cabe perguntar se o entusiasmo dos líderes comunitários pelo Fórum Fome Zero reflete o espírito de mobilização entre seus vizinhos nos bairros. No decorrer de nossa pesquisa, muitos participantes do fórum se queixaram de que a situação incerta daquela conjuntura, com entrega apenas episódica de alimentos, tinha provocado uma desmobilização das associações. ${ }^{17}$ Diziam que "antes", as associações viviam lotadas de voluntários. No auge do Programa Fome Zero, Scalco (2012) tinha testemunhado cenas que apoiavam essa alegação. A cada nova entrega de alimentos, além dos diferentes beneficiados que compareciam para receber cestas, juntavam-se ao redor da associação dezenas de vizinhos para ajudar na distribuição dos alimentos. Havia homens atarefados no

17 Ao que tudo indica, as entregas de alimentos não eram sempre copiosas ou regulares no passado (Ahlert, 2008a, 2008b), mas podemos pressupor que o horizonte político, dando esperança de atender às demandas, era mais otimista. 
descarregamento do produto, mulheres ajoelhadas no chão para confeccionar pacotes iguais, e crianças correndo de porta em porta para avisar que as cestas estavam prontas para distribuição. Até completar a tarefa (o que durava em geral mais do que 24 horas), tinha uma equipe de mulheres que permanecia no local "para proteger os mantimentos" contra roubo ou extravio. As voluntárias se revezavam em pequenos grupos de quatro ou cinco, dormindo no chão, cozinhando e jantando juntas.

A energia gerada nessas ocasiões facilitava a organização de grupos de trabalho, projetos de geração de renda e passeatas para exigir melhores serviços (de saúde, de transporte, de pavimentação) para a vizinhança. Em alguns núcleos, a participação nos eventos da associação era obrigatória para quem queria receber alimentos. Como explica certo coordenador, essa exigência fazia parte de uma "educação política", "no sentido de ensinar, de mostrar o valor que esse cidadão tem". Ainda em 2015, participamos de uma passeata em que centenas de pessoas, oriundas de quase todos os núcleos do município, marcharam para apresentar demandas e escutar esclarecimentos das autoridades estatais sobre o (des)andamento do Programa Fome Zero. Contudo, entre as lideranças do fórum, existe certo consenso: a partir de 2014, ante a irregularidade da entrega de alimentos do CDS, teria ocorrido um esvaziamento das reuniões das associações, um enfraquecimento das demandas coletivas e uma diminuição da "conscientização política" dos moradores.

Conforme certos analistas, esse esvaziamento, assim como o corte drástico do orçamento do Programa Fome Zero no ano prévio à nossa pesquisa, seria resultado de uma reorientação da política federal já em andamento há tempo (Burlandy, 2007; Tomazini; Leite, 2016). Há mais de uma década, o contexto político nacional teria atribuído à entrega de alimentos um papel subalterno em relação ao conjunto de programas elaborados para combater a pobreza no país. Sugere-se que esse tipo de programa, centrado no fornecimento de produtos comestíveis, perdeu espaço para o Bolsa Família e outras formas de transferência de renda. A reorientação não foi só por causa da previsível complexidade logística da distribuição de alimentos. Foi resultado também de uma disputa entre distintas filosofias de intervenção: uma voltada para a importância do capital humano e a capacitação individual, outra com ênfase na mobilização política e participação popular. Esses analistas expressam uma inquietação de que, ao dar preferência a programas envolvendo a transferência 
de renda, o governo federal teria preterido políticas privilegiando a mobilização social (Burlandy, 2007; Tomazini; Leite, 2016).

Amâncio, Serafim e Dowbor (2011) também refletem sobre as diferenças entre um programa de transferência de renda - o programa de renda mínima em São Paulo - e um programa estreitamente associado a organizações de bairro - o Programa Saúde da Família (PSF). Suas observações sugerem que enquanto a renda mínima envolve iniciativas individuais, mediadas por profissionais do trabalho social ou do judiciário, o PSF suscita o envolvimento de ativistas "generalistas" acionando repertórios "contenciosos", tais como, além de reuniões na comunidade, marchas e outras manifestações públicas (Amâncio; Serafim; Dowbor, 2011, p. 308). Insistindo na associação entre o PSF e ações comunitárias, as autoras arriscam a hipótese de que

só fazem sentido ações de mobilização comunitária quando aqueles que a realizam são capazes de identificar interlocutores tangíveis e claros nas instâncias de poder público que são, por sua vez, obrigadas a oferecer respostas às demandas apresentadas. (Amâncio; Serafim; Dowbor, 2011, p. 307).

Nesse sentido, é significativo o comentário de uma das nossas interlocutoras (recipiente de alimentos) sobre suas intermináveis dificuldades em receber o Bolsa Família. Apesar de proferir críticas também ao programa CDS (se queixando da irregularidade de entrega de alimentos), ela desabafa: "Pelo menos, quando não vêm os alimentos, eu tenho onde me queixar." Evidentemente, ela vê no seu núcleo local, a associação comunitária, uma possibilidade de interlocução que não encontra nos serviços da burocracia estatal (Centro de Referência de Assistência Social, Centro de Referência Especializado de Assistência Social) ${ }^{18}$ pelos quais passa para conseguir o Bolsa.

18 O Centro de Referência de Assistência Social (Cras) é responsável pela organização e oferta dos serviços socioassistenciais da Proteção Social Básica do Sistema Único de Assistência Social (Suas). Já o Centro de Referência Especializado de Assistência Social (Creas) oferece apoio e orientação especializados a pessoas que já têm suas situações de risco comprovadas, ou seja, que são vítimas de violência física, psíquica e sexual, negligência, abandono, ameaça, maus tratos e discriminações sociais. 


\section{Considerações finais}

Não é o nosso intuito endossar uma polêmica que pressupõe o caráter mutuamente excludente das diferentes políticas públicas. Os programas de intervenção que visam aliviar a pobreza via distribuição de alimentos têm sido alvo de críticas há décadas (Garcia; Moore, 2012) e, especialmente no Brasil pós-impeachment, não é difícil encontrar documentos na mídia que falam no "fracasso" do Programa Fome Zero. Certamente, a irregularidade inscrita em programas de distribuição de comida faz pouco para garantir uma melhoria duradoura em termos das condições materiais de vida. Mas há de lembrar que a política atualmente em alta (endossada pelo Banco Mundial) - a da transferência condicionada de renda - também é considerada por muitos como solução ad hoc, "maternalista", de institucionalidade fraca e pouco eficaz no combate à pobreza crônica (Lavinas, 2013; Llobet; Milanich, 2014). Entre cientistas sociais contemporâneos, existe um consenso (que nós não disputaríamos) de que, sem uma política governamental sólida e contínua de proteção universal, implicando mudanças estruturais, os programas sociais de intervenção pontual surtirão relativamente pouco efeito (Freitas; Pena, 2007; Lavinas, 2013).

Contudo, no quadro dessa pesquisa, fomos convocadas pelo Ministério do Desenvolvimento Social e Combate à Fome a responder perguntas precisas, colocadas pela realidade com a qual éramos confrontadas. Não cabia a nós fazer um julgamento global, endossando ou descartando determinado programa de intervenção. Nosso objetivo foi aproveitar a abordagem etnográfica para entender os efeitos sutis, muitas vezes imprevistos, de determinado programa envolvendo a entrega de alimentos a famílias e indivíduos em risco de insegurança alimentar. Em resposta às demandas de nosso patrocinador, frisamos que o estudo qualitativo dificilmente chega às conclusões aparentemente contundentes das abordagens teóricas ou, mesmo, quantitativas. Contudo, pode fornecer insights indispensáveis para a realização exitosa de certos objetivos da intervenção social.

Nesse intuito, procuramos, em primeiro lugar, colocar em relevo as diferenças entre entidades enquadradas por um mesmo programa social de intervenção. Ao sublinhar a heterogeneidade de contextos em que certa política se implanta, nossa análise deixa claro que não bastam princípios retóricos, cartilhas ou orientações abstratas ditadas "de cima" para garantir que uma política alcance seus objetivos. A infraestrutura que faz a mediação entre o plano 
idealizado e seus efeitos práticos depende em grande medida da articulação de atores e recursos locais. Esses elementos devem vistos e escutados, abrindo a possibilidade para constantes reajustes no programa original.

Em segundo lugar, ressaltamos a dimensão temporal envolvida na garantia da segurança alimentar, associando rupturas e acidentes imprevistos na biografia das pessoas atendidas a mudanças e irregularidades da política pública proposta para combater a insegurança. Muitos dos estudos quantitativos de políticas públicas se limitam a fazer um levantamento do momento, não levando em consideração nem a frequente mudança de rumo nas políticas sociais, nem as repetidas rupturas nas trajetórias de vida dos beneficiados. Ao evocar as diferentes temporalidades em jogo, o estudo qualitativo lembra aos analistas e gestores que o problema de "efeitos duradouros" de qualquer política social depende tanto dos percalços da administração institucional como das "atitudes culturais" dos beneficiados.

Nosso estudo ressaltou, em terceiro lugar, certos elementos específicos a um programa de entrega de alimentos - elementos raramente mencionadas nos debates políticos, ou, mesmo, acadêmicos. Atentando às queixas das coordenadoras dos núcleos vicinais, fomos levadas a apreciar a importância dos pormenores infraestruturais do programa - não só as complicações burocráticas (que desafiavam a paciência tanto de administradores quanto de lideranças e beneficiados) como também os problemas logísticos envolvidos na produção, transporte, armazenagem, distribuição e consumo de determinados produtos comestíveis. Aqui a materialidade da comida (empacotável, perecível, com determinado volume e forma manuseável) se revela como "ator" que exige uma articulação local para que sua integração no programa social seja eficaz. E, justamente, por ser um produto palpável, facilmente inteligível, a comida abre vias para a possibilidade dos diversos agentes envolvidos exercerem controle sobre sua distribuição. Com esse controle social popular, acena-se para uma alternativa à interminável escalação de medidas burocráticas de avaliação e controle - medidas que, em certos casos, parecem pouco eficientes senão contraproducentes.

Antes de tudo, a vantagem da abordagem qualitativa é a possibilidade de, indo além da medição de corpos e a contagem de produtos, ressaltar a produtividade de determinada política social em termos dos processos de subjetivação. Para melhor entender essa produtividade, evocamos aqui um recente artigo em que o autor sul-africano James Ferguson (2013) comenta políticas de inclusão 
no contexto da África do Sul. Diante dos estragos do atual sistema neoliberal a exclusão de boa parte da população do mercado formal de trabalho e a extrema desigualdade econômica -, o autor questiona a filosofia estatal vigente que coloca o valor da autonomia do sujeito no âmago da dignidade cidadã. Afirma que estudos etnográficos da vida política local na África do Sul demonstram como, em muitos casos, para alimentar sentimentos de pertencimento coletivo, modelos liberais de mobilização parecem menos eficazes do que as formas de organização que se apoiam na interdependência entre vizinhos, familiares e outras pessoas conhecidas. Conforme esse autor, o "liberalismo emancipatório" elabora críticas persistentes a essas formas locais de organização, as rotulando de retrógradas ou paternalistas, responsáveis pela perpetuação da desigualdade social. Ferguson (2013, p. 232, tradução nossa), por outro lado, sugere que o que as pessoas pobres mais temem é a desigualdade associal:

Parece que, para muitos sul-africanos (assim como para muitas outras pessoas do mundo contemporâneo), não é a dependência e, sim, a ausência dela que é assustadora - a ruptura dos laços e a queda no vazio social.

A partir dessas considerações, o autor explica por que endossa certas políticas sociais (mesmo as que reforçam a dependência de determinados membros da família - mães, anciões...) e não outras.

Não pretendemos retomar aqui a longa história de disputa entre diferentes modelos de inclusão/exclusão (ver Lavinas, 2013). Basta dizer que, no Brasil também, há analistas que se inquietam com a possibilidade de políticas sociais contribuírem para uma espécie de desigualdade associal, onde imperariam retóricas legalistas de cidadania em detrimento a uma linguagem inteligivel de cuidado, conexão moral e obrigação responsável (Oliveira, 2010; Peirano, 2006). No âmbito do Fórum Fome Zero, há uma "produtividade" das queixas no sentido em que estas refletem e produzem uma comunidade de conexão interpessoal. É nas relações entre pessoas situadas próximas na hierarquia social (indivíduos que se veem ora como beneficiados, ora como lideranças comunitárias) que encontramos fofocas e acusações mútuas, mas é também nessas relações que as pessoas conseguem botar um "rosto" no processo cidadão. As queixas e as várias estratégias acionadas para enfrentar os desafios do programa falam de estilos diversos de mobilização política. A partir do estudo 
qualitativo, sobressai, antes de tudo, a convicção de que avaliar qualquer programa social em termos exclusivamente de quantidade ou periodicidade seria ignorar a dimensão moral - de cuidado e conexão - que acompanha a consecução do programa nos microterritórios.

\section{Referências}

AHLERT, M. Mulheres de Monte Verde: etnografia, subalternidade e política na relação de um grupo popular com o Programa Fome Zero. 2008. Dissertação (Mestrado em Antropologia Social)-Centro de Filosofia e Ciências Humanas, Universidade Federal de Santa Catarina, Florianópolis, 2008a.

AHLERT, M. Política "da ajuda": notas antropológicas sobre cestas básicas. In: LIMA, R. K. de (Org.). Antropologia e direitos humanos 5. Brasília: ABA; Rio de Janeiro: Booklink, 2008b. p. 318-349.

AMÂNCIO, J. M.; SERAFIM, L.; DOWBOR, M. Microterritorialidade e controle societal. Lua Nova, São Paulo, n. 84, p. 287-314, 2011.

ARAUJO E SILVA, G. C. de et al. O Programa de Aquisição de Alimentos como instrumento de efetivação do Direito Humano à Alimentação Adequada: uma análise da modalidade Compra com Doação Simultânea operacionalizada pela Conab em 2013. 2013. Disponível em: <http://www.conab.gov.br/OlalaCMS/uploads/arquivos/14_09_15_16_06_44_dhaa_e_san_artigo_sober_2014_arquivo_2.pdf $>$. Acesso em: 10 mar. 2017.

BRASIL. Presidência da República. Casa Civil. Subchefia para Assuntos Jurídicos. Decreto $n^{\circ}$ 3.877, de 24 de julho de 2001. Institui o Cadastro Único para Programas Sociais do Governo Federal. Brasília, 2001. Disponível em: <http://www.planalto.gov. br/ccivil_03/decreto/2001/D3877.htm>. Acesso em: 19 ago. 2016.

BRASIL. Presidência da República. Casa Civil. Subchefia para Assuntos Jurídicos. Decreto $n^{\circ}$ 6.135, de 26 de junho de 2007. Dispõe sobre o Cadastro Único para Programas Sociais do Governo Federal e dá outras providências. Brasília, 2007. Disponível em: <http://www.planalto.gov.br/ccivil_03/_Ato2007-2010/2007/Decreto/D6135. htm>. Acesso em: 19 ago. 2016.

BRASIL. Ministério do Desenvolvimento Agrário; Ministério do Desenvolvimento Social e Combate à Fome. Programa de Aquisição de Alimentos da Agricultura Familiar: renda para quem produz comida na mesa de quem precisa. Brasília, 2012. Disponível em: <http://www.mda.gov.br/sitemda/sites/sitemda/files/user_arquivos_64/ CARTILHA_PAA_FINAL.pdf $>$. Acesso em: 19 ago. 2016. 
BRASIL. Ministério do Desenvolvimento Social e Combate à Fome; Ministério da Fazenda; Ministério do Planejamento, Orçamento e Gestão; Ministério do Desenvolvimento Agrário; Ministério da Educação. Resolução no 62, de 24 de outubro de 2013. Brasília, 2013. Disponível em: <http://www.conab.gov.br/OlalaCMS/uploads/arquivos/13_11_04_08_45_13_resolucao_gg_paa_62_-_25out2013.pdf>. Acesso em: 19 ago. 2016.

BRASIL. Ministério do Desenvolvimento Social. Benefícios assistenciais. Brasília, 22 jun. 2015. Disponível em: <http://mds.gov.br/assuntos/assistencia-social/beneficios-assistenciais>. Acesso em: 19 ago. 2016.

BRITES, J.; SCHABBACH, L. (Org.). Políticas para família, gênero e geração. Porto Alegre: UFRGS/Cegov, 2014.

BURLANDY, L. Transferência condicionada de renda e segurança alimentar e nutricional. Ciência e Saúde Coletiva, Rio de Janeiro, v. 12, n. 6, p. 1441-1451, 2007.

CASTRO, H. C. de. A comida na (da) margem: experiências compartilhadas em uma Cozinha Comunitária. 2015. Dissertação (Mestrado em Antropologia Social)-Instituto de Filosofia e Ciências Humanas, Universidade Federal do Rio Grande do Sul, Porto Alegre, 2015.

CASTRO, H. C. de; MACIEL, M. E. Reflexões sobre o método etnográfico para apreensão das políticas sociais no campo da alimentação e nutrição: notas de pesquisa em uma cozinha comunitária. Demetra: Alimentação, Nutrição e Saúde, Rio de Janeiro, v. 10, n. 3, p. 523-537, 2015.

COMIM, F. Sem miséria, mas com fome. IHU, 15 maio 2014. Disponível em: <http:// www.ihu.unisinos.br/noticias/531332-sem-miseria-mas-com-fome>. Acesso em: 17 jul. 2015.

COMPANHIA NACIONAL DE ABASTECIMENTO. Cartilha de compra da agricultura familiar com doação simultânea - CPR-Doação. [s.d.]. Disponível em: <http://www. conab.gov.br/OlalaCMS/uploads/arquivos/63dc985117c4d154786f6900d96af65c.. pdf $>$. Acesso em: 1 jun. 2012.

DISCURSO da Ministra do Desenvolvimento Social e Combate à Fome - Tereza Campello - no evento de lançamento da Ação Brasil Carinhoso, em maio de 2012, no Palácio do Planalto. Brasília, 2012. Disponível em: <http://www.mds.gov.br/webarquivos/acesso_ informacao/institucional/gabinete-da-ministra/discursos/20120513_Discurso\%20 da\%20Ministra\%20\%20Brasil\%20Carinhoso\%201.pdf>. Acesso em: 19 ago. 2016.

EGER, T. J.; DAMO, A. S. Money and morality in the Bolsa Família. Vibrant, Brasília, V. 11, n. 1, p. 250-284, 2014.

FAO; IDB; WB. Brasil: Projeto Fome Zero. Relatório conjunto FAO/IDB/WB/Grupo de Trabalho da Equipe de Transição. Brasília, dez. 2002. 
FASSIN, D. Another politics of life is possible. Theory, Culture and Society, London, v. 26, n. 5, p. 44-60, 2009.

FASSIN, D. Introduction: toward a critical moral anthropology. In: FASSIN, D. (Ed.). A companion to moral anthropology. Oxford: Wiley-Blackwell, 2012. p. 1-18.

FERGUSON, J. Declarations of dependence: labour, personhood, and welfare in southern Africa. Journal of the Royal Anthropological Institute, London, v. 19, n. 2, p. 223-242, 2013.

FONSECA, C. et al. Apresentação. Horizontes Antropológicos, Porto Alegre, ano 22, n. 46, p. 9-34, jul./dez. 2016.

FONSECA, C.; SCALCO, L. A biografia dos documentos. In: FONSECA, C.; MACHADO, H. (Org.). Ciência, identificação e tecnologias de governo. Porto Alegre: Editora da UFRGS: CEGOV, 2015. p. 20-37.

FÓRUM FOME ZERO. Estatuto social. Porto Alegre, 2009.

FREITAS, M. do C. S. de; PENA, P. G. L. Segurança alimentar e nutricional: a produção do conhecimento com ênfase nos aspectos da cultura. Revista de Nutrição, Campinas, v. 20, n. 1, p. 69-81, 2007.

GARCIA, M.; MOORE, C. M. T. The cash dividend: the rise of cash transfer programs in SubSaharan Africa. Washington, D.C.: World Bank, 2012.

GRISA, C.; PORTO, S. Dez anos de PAA: as contribuições e os desafios para o desenvolvimento rural. In: GRISA, C.; SCHNEIDER, S. (Org.). Políticas públicas de desenvolvimento rural no Brasil. Porto Alegre: Editora da UFRGS, 2015. p. 155-180.

LARKIN, B. The politics and poetics of infrastructure. Annual Review of Anthropology, Palo Alto, v. 42, p. 327-343, 2013.

LAVINAS, L. Latin America: anti-poverty schemes instead of social protection. Berlin: desiguALdades.net - International Research Network on Interdependent Inequalities in Latin America, 2013. (Working Paper Series 51).

LLOBET, V.; MILANICH, N. La maternidad y las mujeres de sectores populares en las Transferencias Condicionadas de Ingresos. Un aporte al debate sobre el cuidado y las relaciones de género. Zona Franca: Revista del Centro de Estudios Interdisciplinarios sobre Mujeres, Rosario, v. 22, n. 23, p. 58-69, 2014.

MARINS, M. T. A. Repertórios morais e estratégias individuais de beneficiários e cadastradores do Bolsa Família. Sociologia e Antropologia, Rio de Janeiro, v. 4, n. 2, p. 544-562, 2014.

MORTON, G. D. Acesso à permanência: diferenças econômicas e práticas de gênero em domicílios que recebem Bolsa Família no sertão baiano. Política e Trabalho, João Pessoa, n. 38, p. 43-67, 2013. 
OLIVEIRA, L. R. C. de. A dimensão simbólica dos direitos e a análise dos conflitos. Revista de Antropologia, São Paulo, v. 53, n. 2, p. 451-473, 2010.

PEIRANO, M. A teoria vivida e outros ensaios de antropologia. Rio de Janeiro: Jorge Zahar, 2006.

PIRES, F. F. Comida de criança e o Programa Bolsa Família: moralidade materna e consumo alimentar no semiárido. Política e Trabalho, João Pessoa, n. 38, p. 123-135, 2013.

PIRES, F. F.; JARDIM, G. A. da S. Geração Bolsa Família: escolarização, trabalho infantil e consumo na casa sertaneja (Catingueira/PB). Revista Brasileira de Ciências Sociais, São Paulo, v. 29, n. 85, p. 99-112, 2014.

PIRES, F. F.; REGO, W. D. L. 10 anos de programa Bolsa Família: apresentação do dossiê. Política e Trabalho, João Pessoa, n. 38, p. 13-19, 2013.

PORTO ALEGRE. Conselho Municipal de Assistência Social. Resolução $n^{0} 176$ de 29/04/2013 que altera as resoluções 089/2004, 148/2004, 174/2004, 024/2005, 033/2005, 154/2010 e 159/2010. Porto Alegre, 2013. Disponível em: <http://lproweb.procempa. com.br/pmpa/prefpoa/fasc/usu_doc/res.176.13.pdf>. Acesso em: 19 ago. 2016.

PORTO ALEGRE. Fundação de Assistência Social e Cidadania. Ação Rua estabelece vínculos. Porto Alegre, [s.d.]. Disponível em: <http://www2.portoalegre.rs.gov.br/fasc/ default.php?p_secao=70>. Acesso em: 19 ago. 2016.

RELATÓRIO do Segundo Seminário do Programa Fome Zero de Porto Alegre. Porto Alegre, 2006. Manuscrito.

SCALCO, L. M. Máquinas, conexões e saberes: as práticas de "inclusão digital" em famílias de grupos populares. 2012. Tese (Doutorado em Antropologia Social)-Instituto de Filosofia e Ciências Humanas, Universidade Federal do Rio Grande do Sul, Porto Alegre, 2012.

SHORE, C. La antropologia y el estudio de la política pública: reflexiones sobre la "formulación" de las políticas. Antípoda: Revista de Antropología y Arqueología, Bogotá, n. 10, p. 21-49, 2010.

SILVA, J. G. da; DEL GROSSI, M. E.; FRANÇA, C. G. de (Org.). Fome Zero: a experiência brasileira. Brasília: MDA, 2010.

SORJ, B.; GOMES, C. O gênero da "nova cidadania": o Programa Mulheres da Paz. Sociologia e Antropologia, Rio de Janeiro, v. 1, n. 2, p. 147-164, 2011.

STAR, S. L. Ethnography of infrastructure. American Behavioral Scientist, Thousand Oaks, v. 43, n. 3, p. 377-391, 1999.

TOMAZINI, C. G.; LEITE, C. K. da S. Programa Fome Zero e o paradigma da segurança alimentar: ascensão e queda de uma coalizão?. Revista de Sociologia e Política, Curitiba, v. 24, n. 58, p. 13-30, 2016. 
VAITSMAN, J.; SOUSA, R. P. de. Avaliação de políticas e programas do MDS: resultados: volume I: segurança alimentar e nutricional. Brasília: Secretaria de Avaliação e Gestão da Informação: Ministério do Desenvolvimento Social e Combate à Fome, 2007.

YAZBEK, M. C. O Programa Fome Zero no contexto das políticas sociais brasileiras. São Paulo em Perspectiva, São Paulo, v. 18, n. 2, p. 104-112, 2004.

YAZBEK, M. C. Pobreza no Brasil contemporâneo e formas de seu enfrentamento. Serviço Social e Sociedade, São Paulo, n. 110, p. 288-322, 2012.

Recebido: 12/03/2017 Aceito: 08/08/2017 | Received:3/12/2017 Accepted: 8/8/2017 